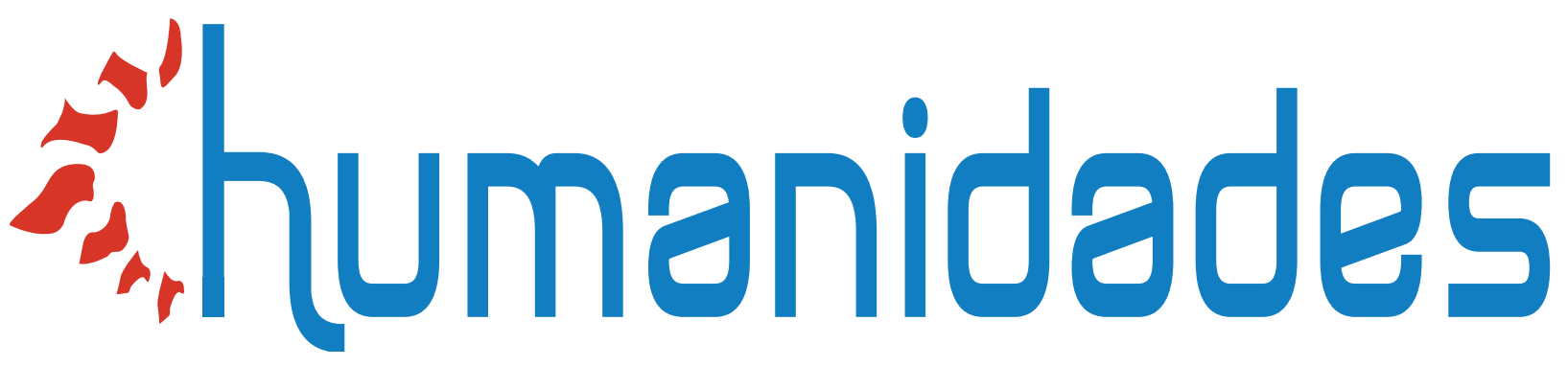

\title{
Razón evaluadora/razón punitiva: relaciones y complicidades \\ (o dos caras de la colonialidad pedagógica)
}

Facundo Giuliano

DOI: https://doi.org//0.155 I7/h.v10il.39678 https://revistas.ucr.ac.cr/index.php/humanidades/index

(c) $(1)(9)$

Universidad de Costa Rica

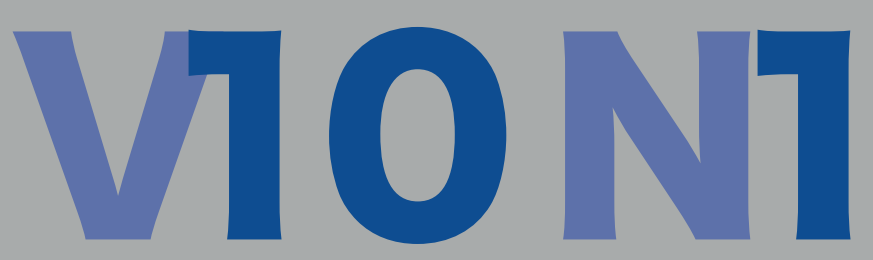




\title{
"humanidades
}

Revista Humanidades

ISSN: 2215-3934

humanidades@ucr.ac.cr

Universidad de Costa Rica

Costa Rica

\section{Razón evaluadora/razón punitiva: relaciones y complicidades (o dos caras de la colonialidad pedagógica)}

\author{
Giuliano, Lic. Facundo \\ Razón evaluadora/razón punitiva: relaciones y complicidades (o dos caras de la colonialidad pedagógica) \\ Revista Humanidades, vol. 10, núm. 1, 2020 \\ Universidad de Costa Rica, Costa Rica \\ Disponible en: http://www.redalyc.org/articulo.oa?id=498060395010 \\ DOI: https://doi.org/10.15517/h.v10i1.39678 \\ Todos los derechos reservados. Universidad de Costa Rica. Esta revista se encuentra licenciada con \\ Creative Commons. Reconocimiento-NoComercial-SinObraDerivada 3.0 Costa Rica. Correo electrónico: \\ humanidades@ucr.ac.cr/Sitio web: http: //revistas.ucr.ac.cr/index.php/humanidades \\ Esta obra está bajo una Licencia Creative Commons Atribución-NoComercial-SinDerivar 3.0 Internacional.
}




\section{Razón evaluadora/razón punitiva: relaciones y complicidades (o dos caras de la colonialidad pedagógica)}

\section{Evaluative Reason/Punitive Reason: Relations and Complicities (or Two Sides of Pedagogical Coloniality)}

Lic. Facundo Giuliano

Consejo Nacional de Investigaciones Cientificas y Técnicas, Argentina

giulianofacundo@gmail.com

(iD http://orcid.org/0000-0003-3404-1612
DOI: https://doi.org/10.15517/h.v10i1.39678

Redalyc: http://www.redalyc.org/articulo.oa? $\mathrm{id}=498060395010$

Recepción: 26 Septiembre 2019

Aprobación: 29 Octubre 2019

\section{RESUMEN:}

La indagación que aquí se plantea intenta poner en evidencia los vínculos y complicidades entre dos tipos de racionalidad que entendemos como dos caras de la colonialidad pedagógica: la razón evaluadora y la razón punitiva. Tal como pensamos este asunto, resulta difícil entender la una sin la otra operando de algún modo más o menos visible dependiendo el caso. Por ello, explorar dichos vínculos en algunos discursos pedagógicos del siglo XX aportará elementos contundentes de análisis que mostrarán hasta qué punto están relacionadas y nuestro presente se encuentra atravesado por ellas. Así, podremos observar cómo la razón punitiva forma parte de la razón evaluadora que no solo judicializa los vínculos pedagógicos al interior de instancias educativas, sino que su afán inclusivo también se encuentra signado por diferentes formas de violencia, crueldad y castigo. Esto también invita a pensar la importancia de interrumpir la sinonimia instalada por la modernidad/colonialidad entre educación y evaluación, como modo principal de resistencia a los regímenes pedagógicos que proto-criminalizan lo considerado "anormal", condenan el error y juzgan toda potencia de alteridad. Por último, se plantea una defensa del error como parte constitutiva de lo que somos y como tentativa para pensar una justicia (pedagógica) de alteridad.

Palabras Clave: Evaluación, Castigo, Pedagogía, Colonialismo, Educación.

\section{Abstract:}

The inquiry raised here attempts to highlight the links and complicities between two types of rationality that we understand as two faces of pedagogical coloniality: the evaluative reason and the punitive reason. As we think about this matter, it is difficult to understand one without the other operating in some way more or less visible depending on the case. Therefore, exploring these links in some educational discourses of the twentieth century will provide strong elements of analysis that will show how far they are related and they cross our present. Thus, we can observe how the punitive reason is part of the evaluative reason that not only judicializes pedagogical links within educational instances, but that different forms of violence, cruelty, and punishment also mark its inclusive desire. This also invites us to think about the importance of interrupting the synonymy installed by modernity/ coloniality between education and evaluation, as the main mode of resistance to pedagogical regimes that proto-criminalize the considered "abnormal", condemn error and judge every power of otherness. Finally, there is a defense of error as a constitutive part of who we are and as an attempt to think of a justice (pedagogical) of otherness.

KEYWORDS: Evaluation, Punishment, Pedagogy, Colonialism, Education.

\section{Preludio: Sobre PEdAgogías de la CRUELdAD.}

Algunos escollos históricos tienden a repetirse, a veces toman nuevas formas, pero permanecen en el solapado mar de las continuidades. Como se ha enfatizado recientemente, la colonialidad pedagógica (Giuliano, $2019 b$ ) busca servidores disciplinados y disciplinantes que, en nombre de "nobles intenciones", clasifican, normalizan, subestiman, desprecian, moralizan. Estos procedimientos involucran al menos dos tipos de racionalidades mutuamente imbricadas, cuyas relaciones y complicidades se indagarán en la travesía que se propone en este escrito, a partir de la búsqueda genealógica en diversas fuentes de comienzos del siglo 
XX y otras de mediados de siglo en adelante. De este modo, entre otras cuestiones, se observará cómo la racionalidad del castigo -o razón punitiva- no es ajena a la razón evaluadora (Giuliano, 2019a).

Por tal motivo, tal vez no esté de más recordar la novela de fines del siglo XVIII, La filosofía en el tocador, en la cual el Marqués de Sade hace hincapié en la idea de que nacemos con una dosis de crueldad que solo la educación puede modificar. Lejos de pensar en el determinismo biológico o genético que subyace en la idea, resulta importante rescatar la potencia de torcer ese determinismo (y cualquier otro) que tiene la educación. No obstante, también es cierto que puede haber ( $\mathrm{y}$ de hecho la hay) una formación en la crueldad, una educación en la insensibilidad hacia quien sufre, una pedagogía de la crueldad. Esta última supone, para Mèlich (2014), hacer de quien sufre un objeto de goce, alguien a quien se despoja de singularidad, en una espacialidad ordenada y calculada, siempre en nombre de la moral (que no procede sin lógica y, por lo mismo, sin crueldad). De forma imperceptible, escondida tras un velo de naturalidad y de "normalidad", la pedagogía de la crueldad así entendida no se reduce a una acción violenta, porque es más sutil, aunque planificada, forma una manera de mirar que ordena (epistemológica, ontológica y moralmente) un sistema de inclusión/ exclusión al tiempo que clasifica en su intento de comprensión.

Rita Segato (2018) habla de las pedagogías de la crueldad para referenciar "todos los actos y prácticas que enseñan, habitúan y programan a los sujetos a transmutar lo vivo y su vitalidad en cosas", lo cual hace de la imprevisibilidad de la vida la instalación de "la inercia y la esterilidad de la cosa, mensurable, vendible, comparable y obsolescente, como conviene al consumo en esta fase apocalíptica del capital" (p. 13). Como en un camino inescapable del legado moderno/colonial, la pedagogía de la crueldad habitúa a la cosificación de lo vivo, al desarraigo, la desensibilización, el racismo y el machismo, elementos que forman parte constitutiva de la razón evaluadora y la razón punitiva respectivamente. Esto último se encuentra planteado en cierta forma al final del libro de Segato (2018) donde se refiere a la evaluación como un suicidio para el pensamiento, en que "el contenido es siempre subordinado jerárquicamente al número" (p. 123), y quien evalúa "no debe sentir compasión” porque eso sería ir en contra de los propios preceptos canónicos de las instituciones educativas modernas "que son masculinos, de rigor, de castigo, punitivos, excluyentes, selectivos, jerárquicos” (p. 124). En la misma línea, Mèlich (2014) también plantea que para poner en marcha una pedagogía de la crueldad es necesario "desactivar la compasión" (p.121). Por otra parte, lo masculino como corporación, como patriarcado presente en las instituciones educativas y en la razón evaluadora, es un señalamiento clave de Segato (2018) en tanto se concibe como "primera pedagogía de poder y expropiación de valor", una "primera lección de jerarquía, aunque la estructura de esa jerarquía haya ido mutando en la historia" (p. 17).

Un acto disciplinador, moralizador y, en algunos casos, hasta vengador, suele encontrarse en la evaluación y el castigo. El mandato de castigo tantas veces ejercido a partir de una sospecha insoportable para quien lo ejerce, intenta enmendar la capacidad de control que un sujeto pierde sobre otro. Segato (2010) ha demostrado que esta misma lógica funciona en la violación. Si en la evaluación la razón evaluadora intenta apropiarse del fruto de la propia práctica de otro/a, una violencia instrumental orientada hacia un valor que promete adquirir o reparar un prestigio, no estaríamos lejos de cierta práctica emparentada con la violación, y por eso mismo para la razón evaluadora es tan importante dar con el "consentimiento" de quien se evalúa.

El punto es cómo funcionan estos procedimientos en educación, cómo se imbrican y complotan sus racionalidades y de qué manera puede oponerse resistencia a los mismos. De ahí que para profundizar radicalmente en "contra-pedagogías", además de profundizar en el "mundo vincular y comunitario que pone límites a la cosificación de la vida” (Segato, 2018, p. 18), es fundamental explorar las fuentes de los discursos en los que se han naturalizado y normalizado la evaluación y la punición, no sin su respectiva cuota de crueldad, en nuestra formación y en la educación de nuestros pueblos. Este será entonces el compromiso ético-político al que intentarán responder las páginas que siguen. 


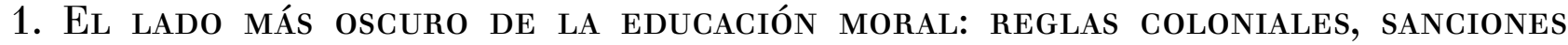 MODERNAS Y RECOMPENSAS EVALUADORAS.}

Si de explorar fuentes se trata entonces, se podría comenzar viajando a través del tiempo y el espacio hacia la Sorbona, de 1902 a 1903, cuando Émile Durkheim dicta su primer curso sobre educación, el cual sería repetido en otras ocasiones. Lo que interesa de este curso, es la segunda parte dedicada a los "elementos de la moralidad" que se traducen en toda una forma de concebir la disciplina escolar a partir de un sistema de penalidad determinado. Tal disciplina y sistema, muestran que no hay regla (impersonal y abstracta) sin sanción (individual). Entonces, si hay un papel moral que la disciplina escolar posee en el planteo de Durkheim (1997), este será el de inculcar y habituar la autoridad moral que encarnaría la impersonalidad y abstracción de la regla. La autoridad moral requiere convicción y fe en "la verdad abstracta de las ideas que expresa" y su "valor moral", lo que constituye un conjunto de caracteres que "eleva por encima de nuestra individualidad empírica, por encima de la media de nuestros semejantes” (Durkheim, 1997, pp. 179-180).

Desde esa posición, Durkheim (1997) piensa la autoridad docente "moderada con benevolencia, de suerte que la firmeza no degenere en rudeza y dureza" y no se conduzca la clase "como un regimiento" (p. 181). El respeto a la disciplina no tendría su origen en el temor de las sanciones que reprimen las violaciones a la regla, porque "una clase bien disciplinada es una clase donde se castiga poco" (Durkheim, 1997, p. 181). Como indisciplina y castigo irían a la par, entonces, el autor se despega de quienes piensan el castigo como prevención e intimidación -a partir de la amenaza que supone- porque actúa desde fuera y no llega a tocar la vida moral en sus fuentes, es decir, aunque puede ser eficaz no llega a ser lo suficientemente "moralizador". También se despega de quienes sostienen que debe ser proporcional a la falta, como si se tratara de una compensación que repararía la infracción y reestablecería el orden perturbado, expiando así al culpable (siempre y cuando este reciba una cuota de dolor proporcional a la falta cometida), pero descuidando que la pena no está totalmente integrada al dolor que causa y que cuando se viola una regla deja de aparecer como "inviolable". Siendo que la infracción moral desmoralizaría y el acto de indisciplina disminuiría la disciplina, la pena aparece como una manifestación significativa del orden moral que un/una docente debe corporizar: "Para esto es necesario que aquél censure de una manera ostensible el acto que se ha cometido, que lo repruebe con energía; esta reprobación enérgica constituye esencialmente la pena" (Durkheim, 1997, p. 188, énfasis nuestro).

Así, la penalidad funciona como productora de tranquilidad de conciencia cuando ha perturbado la fe de quien transgrede -aunque no se haya dado cuenta de ello- y ha dejado claro que la regla o la disciplina mantiene su autoridad corrigiendo el mal producto de la falta. El "tratamiento doloroso" no sería esencial a la pena sino tan solo parte de su manifestación, el signo por el que se traduce exteriormente la búsqueda de neutralización del desorden moral causado, aunque no surtan efecto en las "naturalezas radicalmente rebeldes" (Durkheim, 1997, p. 189). De aquí también sus desacuerdos con Rousseau y Spencer, opuestos a los sistemas artificiales de castigo y donde el mismo medio proveería la "consecuencia natural" o reacción dolorosa que advertiría la falta en una suerte de auto-responsabilización inducida por el castigo impersonal. En particular, se contrapone a tal mirada equiparando al "primitivo" con "el niño" -o al indígena con la infancia- en su supuesta coincidencia en imputar los males sufridos no a una "causa objetiva" e "impersonal" (como podría ser una "ley natural", que no sabrían lo que es) sino a alguien del entorno, y este margen de arbitrariedad le resulta imposible para una enseñanza moral.

Precisamente porque la moral "no es una cosa tan simple", su función reguladora implica que desde esta perspectiva la reprobación de ciertos actos tiene, en todos los organismos sobre los que surte efecto, "repercusiones que no pueden percibirse a simple vista" y "sólo [sic] la ciencia (...) llega a descubrir progresivamente” (Durkheim, 1997, p. 194). De este modo, la reprobación como regulación se relaciona con el hecho de que "las obligaciones a las que está sometido el escolar" no tendrían un fin en sí mismas, pero son reconocidas como ejercicios destinados a preparar "en vista de la vida adulta" sabiendo que: "solamente pues cuando haya salido de la escuela, cuando haya entrado en la vía seria se desprenderán las consecuencias 
naturales" de la conducta escolar y, por ello, es que marca como necesaria la intervención educativa que "una a las reglas de la disciplina sanciones que anticipen las de la vida.” (Durkheim, 1997, pp. 194-195). Así, dice Durkheim (1997), la educación se implica anticipando la "marcha natural de las cosas" y el castigo es la reprobación o la censura que pone al "culpable” en el “índex”, en la dirección del (dedo) índice, en el banquillo de los acusados, lo cual permite cierta separación de otros, cierto vacío en torno suyo, cierto poner a distancia. De modo que el castigo "es un signo material por el cual se traduce un estado interior: es una anotación, un lenguaje" (p. 199), una reprobación como reacción de rigor frente a la falta y cuyos medios encuentran "razón de ser" o justificación en "el fin de reafirmar su sentimiento [de deber] en el culpable y en los que han sido testigos de la falta, la cual tiende a desmoralizarlos" (p. 205).

\subsection{Civilizar y castigar}

Es asombrosa la relación que Durkheim (1997) establece entre "grado de cultura” y castigos de procedimientos "groseros", pues resultaría que los pueblos que llegan a cierto "grado de cultura" prescinden de dichos procedimientos a causa de que su sistema nervioso es "más delicado" y "sensible" a "excitantes débiles" (p. 205). Por eso, para Durkheim, golpes y malos tratos "metódicamente aplicados" son bien comprendidos cuando el castigo requiere una expiación y supone demostrar al sufrimiento como "necesario" para hacer sentir la reprobación. El castigo corporal es admitido así cuando un niño "no es todavía más que un pequeño animal” (Durkheim, 1997, p. 206) y (auto-refutando su anterior tesis) el racismo de Durkheim se profundiza aún más cuando recurre al estudio etnográfico de Steinmetz donde se documenta la disciplina de "gran dulzura" que vio en la educación de muchos pueblos "primitivos" y donde se muestra una ausencia de castigos corporales pero que, paradójicamente, Durkheim concluirá su lectura sosteniendo que, precisamente, las sociedades en las cuales su educación es más severa son las “más cultivadas” y “avanzadas en civilización” que aquellas donde se trata a la niñez con mayor indulgencia:

[...] las sociedades de América han llegado ya, en su mayor parte, a una cierta cultura, aunque evidentemente muy inferior a la nuestra y aun a la de la Edad Media. Pero descendamos un grado en la escala de la civilización. Si no está permitido ya ver a los indígenas de Australia; el tipo perfecto de hombre primitivo, es sin embargo cierto que deben ser clasificados entre los pueblos más inferiores que conocemos. Ahora bien, el niño, lejos de ser maltratado allí, es más bien objeto de mimos excesivos.

[...] De cuatrocientas sociedades que se han comparado hay trece solamente donde la educación es muy severa ${ }^{1}$. [...] Pero lo más curioso es que estos pueblos donde la educación posee ese carácter son relativamente avanzados en civilización [...] son más cultivados que aquellos donde se trata a los niños con extrema indulgencia (Durkheim, 1997, pp. 207-208).

Durkheim mismo da la pauta de que no pueden pensarse las escuelas monacales sin el látigo o el ayuno, del mismo modo que la proliferación y expansión de la vida escolar, durante el siglo XVIII y XIX, no puede pensarse sin la necesidad de reglamentar las "correcciones materiales" cuyos principales procedimientos en Europa incluían: la bofetada, los puntapiés, golpes de puño, de bastón, la encarcelación, el vellicatio y el poner de rodillas, además del látigo (ícono de sellos y celebraciones en su honor) y el ayuno anteriormente mencionados. Incluso menciona que, si bien a fines del XIX se atenuó la tendencia, los principales pedagogos de Alemania $^{2}$ estiman que todavía no conviene prohibirlas completamente. Incluso sostienen que:

[...] hay en la naturaleza de la escuela algo que inclina tan intensamente a este género de castigos, que una vez establecidos persisten durante siglos a pesar de todas las protestas de que son objeto, a pesar de las medidas de prohibición legales más repetidas (Durkheim, 1997, p. 211).

Durkheim se pregunta por las causas de esa disciplina violenta y cómo es que la escuela, ese "hogar de la cultura humana", haya sido, por una especie de "necesidad constitucional", un "hogar de barbarie" (Durkheim, 1997, p. 212) lo que recuerda no solo la idea benjaminiana de que todo documento de cultura es al mismo tiempo un documento de barbarie, sino también la histórica oposición entre civilización o barbarie a partir de la cual Durkheim dice que la "vida del primitivo es simple: sus pensamientos son poco numerosos y 
poco complejos; sus ocupaciones poco variadas" por lo que la educación es "casi inexistente" o posee la "misma simplicidad" a diferencia de la "educación verdadera", que comienza cuando la cultura mental y moral ha llegado a un nivel de complejidad tal que no se puede "dejar al azar de las circunstancias el cuidado de asegurar su transmisión” (Durkheim, 1997, p. 212). Y agrega:

[...] tal acción tiene necesariamente algo de coercitivo y laborioso, pues obliga al niño a sobrepasar su naturaleza de niño, a violentarla, puesto que se trata de hacerla madurar más rápidamente de lo que esta naturaleza supone: puesto que en lo sucesivo en vez de dejar su actividad flotar libremente merced de las circunstancias, es necesario que el niño la concentre voluntariamente, penosamente, sobre los asuntos que se le imponen (Durkheim, 1997, pp. 212-213).

En la última lección sobre "la penalidad escolar", que estaría dedicada a "las recompensas", se encuentran unos pequeños pasajes donde se esboza cierta crítica hacia las compensaciones en tanto "las buenas notas, los lugares, los premios, los honores” desarrollarían más las cualidades de la inteligencia que las del corazón y del carácter asociado a una conciencia "más recta y más delicada" (Durkheim, 1997, p. 229). Previamente, la mayor parte de la lección apunta a consolidar la idea de que "a partir del momento en que la cultura humana hubo alcanzado un cierto grado de desarrollo, los métodos destinados a transmitirla hayan debido adoptar una severidad mayor" y que el "método de las correcciones corporales" se constituyó cuando la humanidad salió de su "barbarie primitiva" y apareció la escuela, porque "la escuela y la civilización son cosas contemporáneas y estrechamente solidarias" (Durkheim, 1997, pp. 215-216). Esto le permite justificar no solo la violencia colonial, incluso en el espacio escolar, sino también le permite delinear toda una "pedagogía del culpable" que lucha contra el espíritu del desorden y de la rebelión que conmueve el pudor moral y hace perder la eficacia del castigo. Esto último le hace pensar en la necesidad de una cierta "economía del castigo" que requiere de una gradualidad en sus maneras, pero que al mismo tiempo evidencie dos cosas: en primer lugar, una decisión deliberada y tomada a sangre fría; en segundo lugar un tiempo transcurrido entre la falta comprobada y la aplicación del castigo (que evita decisiones precipitadas). De esta forma, esta "pedagogía del culpable" produce deudores (no olvidamos aquí que la palabra "deuda" y "culpa” es la misma en alemán "schuld") y Durkheim (1997) lo deja claro cuando dice que cualquiera que cometa una falta en la escuela ha de pagar una "tarifa" (p. 226).

\subsection{El lado más oscuro de la pedagogía: evaluar y castigar}

En el semestre de invierno, entre 1915 y 1916, Georg Simmel impartió sus lecciones sobre pedagogía en Estrasburgo. Dedicó la quinta lección al juicio y la sexta al castigo. A continuación, se expondrán los puntos más relevantes sobre estos dos asuntos.

Desde el inicio, Simmel (2007) advierte la dificultad de juzgar el rendimiento singular de los estudiantes y, más aún, lo que sería su "completa calidad", por lo que enuncia tres tipos de medidas: la medida absoluta (representa el mejor rendimiento que determinada tarea pueda encontrar como mejor "adecuación a la cosa"), la relativa (dada por la edad, la formación previa y el nivel del aula) y la individual (que involucra el talento y los rendimientos hasta allí producidos). A esto agrega que ni el peor ni el mejor rendimiento son buenos o malos en la misma medida y que el "juicio final" se establece a partir del promedio de esos valores en relación con un Todo como: "forma de impresión total que no se conforma desde cada ente singular, y que no concuerda de ningún modo siempre con el promedio" (Simmel, 2007, p. 103). Desde esta perspectiva, es imperativo prestar atención a los errores para removerlos y subrayar "lo bueno y lo correcto". Aquí es donde entran los "trabajos de evaluación", encargados de averiguar qué sabe y qué no saben los discentes, de buscar "lo malo" entendido esto como una "suma de errores singulares" y "lo bueno" como un "carácter del Todo” (Simmel, 2007, p. 104). De esto surgen las singularidades como objetos de la nota que respondería a esa "naturaleza humana" que, para Simmel, le es propio el hecho de privilegiar y desechar como un halagar y criticar, lo que se construye como la esencia particular del acto de evaluar "correcto y natural". Sin estas 
operaciones, Simmel sostiene que cualquier estudiante podría pensar que los docentes no están haciendo realmente su trabajo.

Su posición evaluadora es bastante adelantada para la época desde el punto en que considera el acto de aprender y sus resultados como un proceso vivo "que fluye" y que por lo mismo demanda evaluaciones vivientes (donde el halago y la crítica sean "algo vivo") y no compuestas de "restos muertos" como esas que se conforman de números y predicados fijos que ve como desechables y groseras en tanto "traduce el tratamiento sintomático más burdo" y "desplaza inevitablemente el completo manejo de la lección en la dirección de la mayor enajenación y esquematización imaginable" (Simmel, 2007, p. 105). A raíz de esto, Simmel dice que evaluar se transforma inmediatamente en "locación" y es interesante el término, que nos lleva a la idea de arrendamiento, precisamente que se conecta con la idea de contrato e involucra el uso o aprovechamiento temporal de cosas o servicios a cambio de un precio. ¿Acaso el hecho de lidiar con "restos muertos" no será el precio que se paga por este tipo de locación que es la evaluación? ¿No sería aquí el "contrato pedagógico" un acuerdo entre las partes, en torno a procedimientos de cosificación/mortificación, que toman forma de servicio y siempre luego demanda algún tipo de evaluación?

Luego Simmel, en un llamativo juego de sustitución de términos, resaltará que otra dificultad que radica en el juicio no es solo su justicia sino la percepción de esta por parte del estudiantado. Si esto no sucede, la persona que sea docente no debería escatimar esfuerzos en "convencerles" y evitar "descuidos" en el "camino de la justicia”, como estar convencido de que la tarea impuesta ha sido comprendida -mientras que hay estudiantes que no saben qué hacer- o disponer de una "mirada complaciente general, que cae del patrón de demanda universal” y es percibida fácilmente como una "piedad subjetiva del docente” que sería para Simmel (2007) una de las peores categorías que debe permanecer completamente excluida porque esa forma de tratamiento se torna una "conspiración silenciosa" entre docentes y estudiantes "a espaldas del plan de enseñanza" (p. 106). La prescripción simmeliana para la evaluación, dictamina que no puede ser más benévola en una materia que en otra y, más allá de la moderación o severidad, debería ser “objetivamente correcta” de acuerdo con un "patrón adoptado" (Simmel, 2007, p. 107) que incluya todas las circunstancias que han codeterminado el rendimiento (disposición individual, particularidades del proceso, relaciones bajo las cuales se trabaja, etc.).

Siguiendo con lo anterior, el modelo juzgativo de Simmel pareciera encontrarlo en el "juez de faltas" que no procede con "moderación" (considerada tan arbitraria como la crueldad y comprendida a partir de la mera consideración de factores que intervienen dentro de un rendimiento), lo cual dotaría de cierta estabilidad a los "patrones de medición" que otorgaría tranquilidad y seguridad a estudiantes para rendir (cuentas). No habría así juicio sin rendimiento y viceversa, pero menos aún promedio que pueda emplearse. Pues, para Simmel (2007), cuando se trata de "totalidades humanas" el promedio es en absoluto un procedimiento empleable porque (al igual que las obras de arte que de humanidad está investida) se trata de un ser de tipo particular que "no es designable en absoluto un concepto de valor" (p. 108, énfasis del original). Quizá la trampa esté en ese "un" subrayado que habilita a pensar en una posible multiplicidad de valores consecuentes con una multiplicidad de juicios o evaluaciones, ya que en ningún momento muestran oposición alguna a dichos procedimientos. Aunque no deja de ser importante su argumentación con respecto al por qué un estudiante no puede ser puesto en un rango de acuerdo con el promedio de sus rendimientos, por la falsedad que implica en tanto el ascenso y la caída del rendimiento son tan solo "una imagen de valor particular, solo propia de la vida" (Simmel, 2007, p. 109).

El "sinnúmero de puntos" por donde el "desarrollo vivaz" circula son muy desiguales e inarticulados cuando intentan ser medidos por alguna escala de valor pretendidamente "objetiva”, quizá por esto es que Simmel (2007) insta a una "imagen unificada del juicio escolar" que no debe componerse de "juicios singulares aislados" (en donde su secuencia sería indiferente) sino de acuerdo a "un sentimiento por la vida en desarrollo, que fluye a través de ellos y su sucederse, y por su valor propio" (p. 109). De aquí que "la promoción" no deba ser una "recompensa por los rendimientos" (no debe mirar para atrás) sino basarse en el "juicio completo" que se atendría al último nivel alcanzado y no a la calidad que lo antecedió, lo cual 
sugiere una especie de tabula rasa del rendimiento en sintonía con la abolición del promedio y la proliferación de evaluaciones en tiempo presente que hablen del estudiante que es (y no del que fue), como un tipo de evaluación "en vivo", en "tiempo real" aquí y ahora que tenga una plena capacidad de determinación ontológica por encima del pasado.

\subsection{El castigo "pedagógico", o cuando se necesita convencer del castigo a quien se castiga}

Pues no se puede ser juez a medias y aunque el castigo, por pedagógico que se pretenda, intente no destruir la auto-confianza del estudiantado es al menos complejo no lesionar los núcleos sobre los que podría afirmarse un "desarrollo nuevo" o "reformado" (Simmel, 2007, p. 116). Y es que el castigo implica ya una desconfianza y una condena que podría causar un daño interno (también intelectual) semejante al que causa un reto injusto, un descuido, un tratamiento desentendido de la singularidad que, mediante una palabra enunciada, podría obstaculizar o deprimir. Por eso no extraña que, para Simmel, la "mejor forma del castigo" sea la que convence o hace comprender a quien se castiga del hecho de que lo merecía al haber obrado de modo incorrecto. La apropiación del castigo por parte quien es castigado(a) demostraría cierta confianza que impactaría directamente en su autoconfianza y alimentaría el propio juicio estudiantil. De modo que para esto Simmel (2007) recomienda al docente ciertas imposturas o recursos que le posibiliten "conquistar el corazón” (p. 117) para conducirlo a juzgar correctamente el hecho, por ejemplo, dar transitoriamente la razón o ubicarse en la misma posición -meros mecanismos de inducción-.

Simmel mismo es consciente de que toda pena produce efectos de precaución, cuando no de paranoia, pero no despierta deseo de aprender y, cuando se aprende por miedo (de memoria), se olvida más fácil que cuando se lo hace por deseo o amor. Por tanto, subordinarse a la ley, comprender la propia incorrección e introyectar el "derecho al castigo" termina por legitimar la eterna condena del error, la coerción como valor ineludible y condición de un tipo de aprendizaje impostado, la denostación de algo tan inevitable como la equivocación no es más que un alimento para la repulsa. No obstante, se sostiene en el dolor del castigo un objetivo de mejora que Simmel tiene claro que no se alcanza siempre. Quizá por ello mismo es que se opone a las tareas escolares como castigo, ubicándolas del lado pasivo de la vida y haciendo sentir repulsión por ellas, haciendo que el trabajo no se acerque como algo satisfactorio o que estimule el "sentimiento de vida", aunque estaría plenamente justificado cuando se está frente a un "haragán inmejorable”, cuando se puede decir:

[...] a ese ser el trabajo no le será nunca una alegría y necesidad interior - entonces, uno no debe temer mucho el amargarle el trabajo por medio de que se le encargue como castigo-. Por lo menos, el trabajo de castigo le enseñará al haragán que su vagancia sólo le depara más trabajo. Que no se deje pasar el subrayar esto como ley general de la vida (Simmel, 2007, p. 121, énfasis del original).

\subsection{Entreacto: algunas reflexiones luego de tantas lecciones sobre el castigo}

En una de sus lecciones, Durkheim se pregunta si las relaciones entre docentes y estudiantes no son en muchos aspectos similares a las que se establecieron entre colonizadores y colonizados o a las que suelen establecerse entre generaciones más antiguas y nuevas generaciones en "países civilizados", fundamentalmente en lo que a sus características ineludiblemente violentas refiere. Su interrogación retórica avanza y pregunta si no hay algo de "megalomanía" en el fondo de la pedantería que caracteriza su fisonomía profesional, pero rápidamente se responde como inevitable no adquirir de sí mismo un sentimiento exagerado que se traduce en el gesto, en la actitud, en el lenguaje, "Cuando se está perpetuamente en relación con sujetos a los cuales se es moral e intelectualmente superior" (Durkheim, 1997, pp. 218-219). Así pues, el llamado a un "esfuerzo de paciencia" para con quienes son considerados(as) inferiores, la justificación de manifestaciones violentas o la irritación por la simple dificultad en obtener los resultados deseados caracteriza la escena pedagógica desigualitaria por 
excelencia, que es la base de la colonialidad pedagógica (Giuliano, 2018) y sus caras que encarnan la razón evaluadora (Giuliano, 2019a) y la razón del castigo -o racionalidad punitiva-. Tal vez sería oportuno, antes de pasar a algunas puntuaciones intermedias, interpretar un fragmento que ilustre con precisión el racismo epistémico y la colonialidad pedagógica:

Siempre que dos poblaciones, dos grupos de individuos, pero de cultura desigual, se encuentran en contactos seguidos, se desarrollan ciertos sentimientos que inclinan al grupo más cultivado o que se cree tal, a violentar al otro. Es lo que se observa tan corrientemente en las colonias y en los países de todo género donde los representantes de la civilización europea se encuentran en contacto con una civilización inferior. [...] De aquí esta especie de locura sangrienta que asalta al explorador en sus relaciones con razas que juzga inferiores. Esta superioridad que se arroga tiende, como por sí misma, a afirmarse brutalmente $[. .$.$] por el placer de afirmarse. Se produce una verdadera embriaguez, como exaltación exacerbada del yo, una$ especie de megalomanía que arrastra los peores excesos, y de la cual no es difícil percibir los orígenes. Hemos visto en efecto que el individuo no se contiene más que si se siente contenido, si se ve en frente de fuerzas morales que respeta y a las cuales no se atreve a violentar. [...] Estas violencias son un juego para él, un espectáculo que se da a sí mismo, un medio de testimoniarse esta superioridad que él se reconoce. Es este, verosímilmente, un fenómeno del mismo género que se puede observar en los paises civilizados siempre que un grupo de antiguos y de jóvenes se encuentran en contacto [...] Los antiguos se sienten superiores a los nuevos porque son [...] los depositarios de los usos y de las tradiciones que los nuevos ignoran (Durkheim, 1997, pp. 216-218, énfasis nuestro).

Algunas ideas que los enunciados de esta "lección" (con toda la ambigüedad del término) permiten inferir podrían ser que:

I. No habría desigualdad sin la pre-suposición o auto-afirmación de un superior.

II. La presuposición de desigualdad entraña diferentes formas de violencia.

III. La manifestación de una "locura sangrienta" se relaciona con relaciones que tienen como base un juicio o evaluación que, por su propio proceder, establece inferioridades que deben de ser sometidas.

IV. La crueldad posee una dimensión de escenificación y espectáculo que tiene al yo como protagonista y, mediante sus actos, intenta corroborar la falsa superioridad que se atribuye.

V. Cuando la palabra "civilización" funciona como adjetivo se postula un axioma racista y desigualitario.

VI. El sentimiento de superioridad de unos se afinca en un depósito de usos y tradiciones que serían ajenas a otros contra quienes justificarían sus violencias en nombre de una idea de coherencia corporal y unidad espiritual que hacen pesar sobre quienes no comparten su común, su constitución y organización.

Para finalizar esta primera parte, hemos visto que en Durkheim la razón punitiva actúa junto con la razón evaluadora cuando encontramos la reprobación como regulación de la vida presente con proyección hacia el futuro, es decir, como forma de garantizar la imposición de reglas impersonales y abstractas cuyos efectos de penalidad recaen sobre sujetos singulares. La reprobación como búsqueda de penalización y corrección de la falta pone en juego una "pedagogía del culpable" que en tanto los sujetos producen faltas, al mismo tiempo emiten deudas que deberán saldar mediante algún tipo de "tarifa". Además, la relación establecida entre severidad y educación moral verifica la tesis de Mèlich (2014) sobre el hecho de que en toda moral opera una lógica de la crueldad y agregamos que sin severidad no habría razón evaluadora ni razón punitiva. Por lo que, si civilizar implica, en cierto modo, castigar, vemos que la razón evaluadora y la razón punitiva se invisten de la autoridad moral que habilitaría esa "elevación por encima de la medida de los semejantes" en nombre de la cual se monta la educación moral.

Por su parte, Simmel nos permitió verificar aún más las relaciones entre razón evaluadora y razón punitiva cuando su postulado evaluativo de lo viviente parte del objetivo de remover, descalificar, excluir el error, pagando un precio por ello -en lo que remite a su idea de evaluación como locación- en función de un "patrón de demanda universal” -que bien lo podríamos pensar como patrón colonial de poder, siguiendo lo analizado en Giuliano (2019c) a partir de Aníbal Quijano- y que requiere tanto convencer de la sentencia a quien se juzga como convencer (o "hacer comprender") del castigo a quien es castigado. Este procedimiento de "conquista del corazón" o búsqueda del consentimiento es típico de la razón evaluadora y vemos por Simmel que también lo es de la razón punitiva, de aquí que puedan pensarse estas racionalidades como dos caras de la 
colonialidad pedagógica. Esta última también se manifiesta en Simmel cuando asocia el "castigo pedagógico" con un "estadio de desarrollo humano más alto" y cuando hace tabula rasa para evaluar lo que supuestamente se es en detrimento de lo que meramente está (estar que se constituye, entre otras travesías, a partir de esas vagancias de la memoria involuntaria por unas verdades quizá tenebrosas para saberes pretendidamente lúcidos).

Tal vez para que la labor de la docencia no se reduzca a la tarea de un juez de faltas que omite la moderación, o para que la tarea pedagógica no sea la de saber cuándo castigar y cuándo no, o la actividad del estudiantado no sea la de introyectar o apropiarse las razones de la evaluación y el castigo, tal vez tengamos que hacer como la mujer que derribó un muro (o un gigante) con una pluma:

Con caracteres pequeños, caligrafía desgarbada y desde el ángulo superior izquierdo [...] la pluma rasgó la superficie y se adelantó, desde entonces, con un trazado incierto [...] Se disparó en haces o se enroscó en eses, pero no llegó a dispersarse en relación con sus núcleos; como si el terror a la superficie ilimitada la condicionara, fue creando zonas de reserva, señuelos de referencia a los que podría volver si se perdía [...] la pluma se apoyaba sobre su punta o se deslizaba de canto, era punzón o gubia, sin prever de qué manera [...] eludir el carácter efímero de sus incisiones [...] y el muro, sobrecargado con una violenta energía, traspasado y transido por la grafía, expuesto a una intemperie desconocida hasta entonces, constreñido por su foso y dominado por un prolongado sitio, se fue cayendo, literalmente, sobre la línea recta de su base; no se desmoronó arrojando cascotes como edificio de terremoto, sino que se filtró sobre su línea fundante, como un papel que se desliza vertical en una ranura (Mercado, 1990, pp. 196-197).

\section{Palabra no dicha, pero racionalidad latente.}

Si prestamos atención a los discursos que justifican de algún modo la racionalidad evaluadora, al menos desde mediados de siglo XX en adelante, y tal vez, por los efectos de la posguerra, la palabra castigo desaparece de los textos dedicados a la evaluación. No obstante, ello no quiere decir que la razón punitiva haya desligado sus vínculos con la razón evaluadora. Más aún, parecieran haberse tornado tan sutil, presente y efectivo que el asunto ya no requiere de apartados específicos que aclaren límites o restricciones. Antes bien, ahora el castigo pervive en el corazón de la razón evaluadora y algunas citas clave podrían ejemplificar el asunto.

En 1967, el psicólogo educacional conductista norteamericano Robert L. Thorndike, junto a Elizabeth P. Hagen, publica un voluminoso libro titulado Medición y evaluación en psicología y educación. Allí, desde un enfoque profundamente conductista y liberal, ambos dedican un capítulo a los problemas sociales y políticos de la evaluación, dicho capítulo comienza subrayando la influencia de las pruebas estandarizadas en los últimos setenta años de aquel entonces en Estados Unidos y cómo "se han extendido en variedad y amplitud a tal grado de que, de un modo u otro, influyen en la vida de casi todas las personas" (Thorndike y Hagen, 1989, p. 589). La operación del capítulo intenta examinar algunos de los peligros e inequidades que se han adscrito a la evaluación, "inquirir el mérito de sus críticas" y sugerir precauciones para satisfacerlas de modo que la evaluación se maneje de tal forma que "maximice los valores individuales y sociales, mientras que minimice los peligros individuales y sociales” (Thorndike y Hagen, 1989, p. 590). Sintomáticamente, la dimensión social y la dimensión política de las cuestiones, quedan soslayadas o reducidas al plano individual cuando trazan algunos criterios para intentar contrarrestar la mirada de la evaluación como una amenaza a los derechos individuales, dicha amenaza es focalizada bajo tres aspectos:

I. Invasión de la privacidad (si bien todavía ni siquiera habían llegado las redes sociales, se cuestiona el requerimiento de información personal y su uso posterior, para lo cual reivindican la práctica del "consentimiento informado" y, en la medida de lo posible, el resguardo del anonimato).

II. Autoincriminación y derecho a refutar (para lo que proponen puesta a disposición de resultados y más instancias de evaluación en caso de ser necesarias).

III. Riesgo físico o psicológico (a la angustia, la preocupación o la auto-depreciación que las pruebas generan proponen hacer hincapié en sus beneficios y "estar alertas" contra la tendencia a denominar y clasificar "solo por el deseo de hacerlo" (Thorndike y Hagen, 1989, p. 596), como si el mero hecho de "describir" 
a una persona y leerlo desde cierta totalidad -tal como postulan- no tuviera efectos denominadores y clasificatorios).

Por supuesto, el siguiente apartado, desarrollado con mayor énfasis y extensión, se dedica a los beneficios individuales de las pruebas, pero lo que aquí nos interesa mostrar es que cuando la razón evaluadora aparece acompañada de una amenaza o de vivencias que entran en el orden de algún suplicio eso nos indica que la razón punitiva se encuentra presente, por más que no sea (explícitamente) dicha.

Otro conductista, pero con otra incidencia en el campo educativo por sus estudios sobre el currículum, dirá en 1969 -en el que fuera "el libro del año sobre educación"-:

Puede afirmarse, en un resumen equilibrado de la situación actual en el mundo, que los exámenes tienen profundos efectos educacionales en muchos alumnos y maestros. En el caso de los alumnos que tienen cierta confianza en su capacidad de rendir examen, saber que será necesario afrontarlos constituye un vigoroso estímulo del estudio, y el informe ulterior acerca de las notas asignadas a su desempeño aporta un poderoso mecanismo de refuerzo de la recompensa o el castigo que contribuye a sostener la motivación de aprendizaje (Tyler, 1971, p. 243).

El texto fuente en su amplitud refiere a los efectos “educacionales" de los exámenes y, como puede leerse, se los afirma como "estímulo para el estudio" al tiempo que el desempeño traducido en una nota funcionaría, naturalmente, como un poderoso mecanismo de refuerzo que, más allá de si recompensa o castiga, contribuye a sostener la "motivación de aprendizaje". Una argumentación, por cierto, casi idéntica a la que realizan en el presente cercano Simons y Masschelein (2014) en su defensa de los exámenes -lo cual ya fue analizado en Giuliano (2019b)-. Pero, para no ir hacia otras discusiones, sería conveniente realizar un salto hacia finales del siglo XX cuando, en 1997, el sociólogo suizo Philippe Perrenoud se pregunta si trabajar bajo amenaza es aprender y, entonces, da cuenta de cómo se ejerce una fuerte presión sobre el comportamiento cuando la libertad de los niños y las niñas, y adolescentes depende de sus notas. $\mathrm{O}$ cuando, por ejemplo, se les retira el amor y la estima si tienen malos rendimientos -o se los ama y ensalza en el caso contrario-. Si bien no habla expresamente de castigos, pone de manifiesto claramente la íntima relación de la razón evaluadora con la razón punitiva cuando un mal rendimiento convierte a alguien en un "mal alumno" pasible de temer, según sea el caso, ironías, hostilidad, algún tipo de separación o, directamente, una derivación al gabinete psicopedagógico. El problema de Perrenoud (2015) es que ve solo en el "sistema de evaluación tradicional" una extorsión de una relación de fuerza más o menos explícita que sitúa a estudiantes y docentes en dos campos diversos: "unos intentando preservar su libertad y tranquilidad, otros esforzándose por hacerles trabajar 'por su bien'” (p. 92); y no ve la forma que toma tal extorsión, esa suerte de "juego del gato y el ratón" donde se enfrentan estrategias y contra-estrategias, en la evaluación "formativa" que defiende como transparente, colaborativa e impoluta de competencia, conflicto, hipocresía. Pues, ciertamente, la ilusión de las relaciones cooperativas exentas de extorsión que la evaluación "formativa" presupone, oculta o disimula hábilmente el juicio (normalizador/clasificador) que, más tarde o más temprano, los(as) docentes realizarán sobre los(as) estudiantes.

Sobre dicha extorsión y el refinamiento de la hostilidad con el pretexto del "propio bien", podría traerse a cuento un libro aparecido en 1980 en el que la psicoanalista alemana Alice Miller reúne una serie de indagaciones, de fuentes pedagógicas del siglo XVIII y XIX, en torno a las "raíces de la violencia en la educación" y en cuyo título lleva la contundente frase oída en más de una ocasión "Por tu propio bien". Siempre queda la duda sobre el bien de quién se trata o por qué se insiste tanto en la propiedad del bien, pero para no desviarnos del asunto interesa su señalamiento acerca de que, con esa excusa, "hay toda una escala de medidas refinadas que se aplican" (Miller, 1998, p. 30) y que suelen tener efectos devastadores en la vida de los sujetos. Si hacemos foco en esa escala de "medidas refinadas", podemos encontrar testimonios de docentes que consiguen la obediencia de estudiantes sin necesidad de recurrir a golpes o, en palabras foucaultianas, realizando un cambio en la economía del poder, por ejemplo, valiéndose de la persuasión o de un ejercicio de convencimiento (que incluye su propio comportamiento) de que se actúa por su propio bien y 
se demuestra, mediante ejemplos y comparaciones, los perjuicios de la desobediencia al tiempo que se ofrecen "recompensas" para la complaciente obediencia y aplicación.

Como dice Miller (1998), "La máscara de la amabilidad ayuda a ocultar aún mejor la crueldad del tratamiento" (p. 35) y esto ha incluido un repertorio metodológico tan amplio como insólito que ha ido mutando o tomando otras formas a lo largo de la historia, tal como lo documenta Miller (1998); desde los suplicios de la violencia física y de la tortura hasta la transmisión de informaciones e ideas falsas, pasando por el hecho de "tender trampas, aplicar la astucia, disimular, manipular, amedrentar, quitar el cariño, aislar, desconfiar, humillar, despreciar, burlarse, avergonzar" (p. 66). Miller encuentra, en los consejos educativos y las prácticas pedagógicas que incluyen este tipo de procedimientos, necesidades de la adultez (o de la mayoría de edad kantiana) cuya satisfacción interrumpe e impide el crecimiento vital de las infancias (incluida la del propio cuerpo docente). Entre ellas, menciona la necesidad inconsciente de transmitir a otras personas las humillaciones padecidas antes, la necesidad de encontrar una válvula de escape para los sentimientos reprimidos, así como la necesidad de poseer un objeto vivo disponible y manipulable, la "defensa propia" o corroboración de la rectitud de los principios pedagógicos, el miedo a la libertad y al retorno de lo reprimido, y "la venganza por los sufrimientos padecidos" (Miller, 1998, p. 101). En tal marco, siempre estaría en juego al menos una de las necesidades o motivos mencionados y es entonces cuando toman relevancia algunas interrogantes como, por ejemplo, “¿cómo vivo yo la violencia de mi formación? ¿Cómo vive esta en mí? ¿Cómo me lleva a mí, a pesar de mí, al tiempo que yo la llevo a ella? Y ¿en nombre de qué nuevo valor puedo yo dar marcha atrás e impugnarla? ¿En qué sentido puede dicha violencia ser redirigida, si es que puede serlo?” (Butler, 2010, p. 234).

Ya habiendo transitado alguna formación en medio de la violencia, la cuestión radica en qué puede hacerse con la acción pedagógica que continúa a lo largo de toda la vida sin descuidar el dilema ético de cómo vivir la violencia de la propia historia formativa y efectuar cambios e inversiones en su reiteración, siendo que esta última rehúye a todo voluntarismo o determinismo y, por ello mismo, sitúa a todos en una lucha contra la violencia. Una lucha que también implica desanudar de lo educativo estos vínculos de la racionalidad punitiva con la racionalidad evaluadora que no solo afectan a estudiantes, sino también a docentes. Tal y como Capurro y Nin (2018) han documentado para el caso de la maestra uruguaya Iris Cabezudo Spósito, quien destacaba el sostén, el apoyo y la colaboración como tres rasgos que potenciaban su práctica docente por parte de colegas que se hallaran en un escalafón superior y no caían en una "función fiscalizadora" de su práctica, una función que (conjugando la racionalidad evaluadora y la racionalidad punitiva) a ella le hizo escribir a mediados de siglo XX:

Los informes y calificaciones que figuran en mi foja de servicios, ¿reflejan en verdad mi forma de trabajar, mi capacidad, mi entrega total al trabajo y al rendimiento que ese trabajo tuvo con mis alumnos? Evidentemente, no. Entonces, ¿qué objeto tiene? [...] salvo excepciones, nuestro sistema escolar, en la actualidad está regido por el temor. [...] Nuestra escuela se queda en lo formal, en lo que alcanza para cubrir una prueba. [...] Nuestra escuela no educa; nuestra escuela no forma: nuestra escuela amaestra y anula (En Capurro y Nin, 2018, pp. 436-457, énfasis del original).

\section{1 ¿"Ética” del castigo?}

El énfasis en el que una escuela que se centra en la prueba, en la razón evaluadora de ser y hacer, que se rige, además, por el temor que ella infunde -por las consecuencias que supone-, es una escuela que no educa, sino que amaestra y anula, puede compartirse en el marco de este análisis que también involucra a la razón punitiva. Algo que también puede observarse de otro modo en el libro Ética y escuela de la pedagoga australiana Felicity Haynes, quien hacia finales de siglo XX, hace reaparecer el significante castigo, pero ahora asociado a cierta "ética". Así, desde una perspectiva utilitarista y con-secuencia-lista, Haynes (2002) habla de la "ética" del castigo de modo que ciertos castigos puedan considerarse medios para alcanzar un fin si se emplean para conseguir un efecto beneficioso -tal como dejar claras las consecuencias del incumplimiento de las normas, 
lo que "enseñaría" los efectos positivos o negativos de una conducta y tornaría la intención más "instructiva" que punitiva-. Lo cual no abandona la racionalidad punitiva y busca teñir de "ética”, los fines de la culpa; y de "justicia”, el descuido.

De ese modo, se justifican castigos como anotar el nombre de quien sería “infractor(a)" en el tablón de anuncios, el sermón normalizador (que moraliza sobre la importancia de la norma), la expulsión del espacio pedagógico y la derivación a alguna autoridad superior, el castigo diferido que impacta en las horas pos-áulicas, la disculpa ejemplar frente al curso, la sobrecarga de tareas durante algún período, la escritura repetida de por qué lo hizo y por qué es importante que no lo vuelva a hacer, la pérdida de privilegios en la biblioteca, etc. Todo lo cual apunta a considerar el castigo compatible con los fines de la educación de manera que se reconozca y afirme "el carácter de persona de quien es castigado: si trata a la persona como a un sujeto que merece justicia” (Haynes, 2002, p. 83, énfasis nuestro), lo que no solo reduce la justicia al juicio y al castigo, sino al cruel "dispositivo de la persona" que distingue lo que tiene primacía ontológica frente a lo que no lo tiene y, por ello, es reducido a cosa -asunto que ya ha sido analizado en relación a la educación (véase Giuliano, 2019c)-.

Desde dicho planteamiento, el castigo vuelve a la escena como "una parte inseparable de cualquier esquema moral en el que se valoren y se pretendan alcanzar la justicia y la responsabilidad personal" (Haynes, 2002, p. 88), y cualquier docente que "proteste y ponga en entredicho los diversos medios de control social del aula, y los fines que justifican esos medios" es considerado un "sujeto resistente" que "se niega a someterse al discurso local dominante" (Haynes, 2002, p. 85). Como si se tratara de un remake maquiavélico del castigo, esta posición insta a considerar siempre si el fin justifica los medios, incluso si se trata del "uso de picanas eléctricas para modificar la conducta de los niños autistas" (Haynes, 2002, p. 88) algo que no podríamos plantear en ningún umbral de consideración desde una perspectiva ético-política. Por tal motivo, consideramos que el planteo de Haynes se ubica en una posición principalmente moral y no ética tal como podríamos entenderla aquí -en disyunción con la moral y no como su mera continuidad-. Ahora bien, Haynes evidencia con contundencia el vínculo o la connivencia entre razón punitiva y razón evaluadora cuando plantea la disciplina asertiva (aquella que utiliza el placer y el dolor -o ambos- para sancionar los comportamientos considerados "inaceptables" y reforzar los considerados "correctos") no solo como un instrumento de control para dirigir la conducta hacia fines "deseables" sino, sobre todo, para orientar la elaboración del propio juicio como una manera de conducir hacia la "autonomía".

Si su utilitarismo queda en evidencia cuando ve en las lógicas restrictivas un basamento "ético" (más bien moral, diríamos) que maximizaría la felicidad minimizando el daño, al tiempo que garantizaría el "tranquilo" funcionamiento de la escuela como finalidad de dichas lógicas, el espectro kantiano superyoico se presentifica cuando aparece su exhortación al sujeto autónomo, a la autonomía de la razón que, vía conciencia o "voz interior", indicaría "hacer lo que se cree correcto" como forma de ejercer el "juicio racional", aunque ello implique hacer lo que no esté determinado por la ley. Una posición individual pretendidamente universalista y lavada de heteronomía o, en otras palabras, lavada de toda potencia de alteridad que hace a la presencia de un otro en la escena decisional.

En este marco, la posición docente se reduciría a la de un "administrador educativo" que debe "asumir cierto grado de responsabilidad por presionar a determinadas personas a acomodarse a las normas" (Haynes, 2002, p. 95, énfasis nuestro) lo que hace de la "autonomía" un gesto dudoso y de la docencia una militancia de la normación y la normalización. Eso sí, habría en esta posición administrativa una "dialéctica" o "mezcla" de acciones deliberadas o escogidas "libremente" y restricciones del entorno -en el que se incluye a la culpa como medio de control social aparejado a la noción de responsabilidad individual que elude el juego de interrelaciones e interdependencia que constituye a los sujetos en forma no autónoma-. De modo que, como en todo asunto administrativo, inevitablemente hay un momento de "rendición de cuentas" que Haynes enlaza al de la evaluación. En este contexto "contable", no es menor la referencia a la culpa que hace la autora puesto que, como ya advirtió Nietzsche (1997), el sentimiento de culpa ha tenido su origen en la relación 
entre compradores y vendedores, acreedores y deudores, una primera forma de relación en que "las personas se midieron entre sí" (p. 91).

De una autora que se manifiesta a favor de la pena de muerte, porque se justificaría como "medio desagradable" para el fin "disuasorio" ${ }^{3}$ que tendría, no extraña leer que para ella el castigo puede ser ético y la evaluación "un medio para un fin educativo" o, directamente, "un fin en sí mismo" (Haynes, 2002, p. 95). Algo que, insistimos, no solo afecta a estudiantes sino también a docentes ya que:

En la tendencia global hacia la rendición de cuentas, se aboga por un sistema de pagos en función de los resultados, en el que los resultados de una clase [...] se comprueban al principio y al final de cada curso escolar, y al profesor se le promociona, se le asignan grupos buenos o malos, o se le baja de categoría, en función de si su clase ha mejorado o no en su conjunto, dando por supuesto que los resultados de los tests ofrecen las pruebas adecuadas del mérito del profesor (Haynes, 2002, p. 96, énfasis nuestro).

Con objetivos a corto plazo convertidos en normas de rendimiento, las evaluaciones serían un fin en sí mismas si se pretende escalar posiciones y evitar consecuencias penosas o punitivas. El planteo de Haynes, entonces, no hace otra cosa que mostrar los límites de la "importante transformación" que Foucault (2009) reconoce en una de las reglas claves de la semiotécnica con la que se arma el poder de castigar, esta es, la "regla de la verdad común" cuyo "antiguo" sistema inquisitorial de pruebas (el uso de la tortura, el arrancar de una confesión por la fuerza, la utilización del suplicio, del cuerpo y el espectáculo para la obtención de una supuesta verdad) adoptaría el modelo mucho más flexible de la investigación empírica (que combina ciencia y sentido común), pero evidentemente no se habría desembarazado (al menos del todo) de su(s) forma(s) anterior(es). Si Haynes misma documenta experiencias recientes de suplicios públicos, castigos ejemplares, así como cierta publicidad o difusión del vejamen, podemos notar que, aunque en algunos casos el castigo sea más sutil y se verifique cierta economía del poder punitivo, en otros, la lógica inquisitorial y del suplicio demuestra su pervivencia al interior de la racionalidad punitiva que forma parte de la razón evaluadora. Esto forma parte de lo que Foucault (2009) llama la "tecnología de representación" sobre la que se apoya el "arte de castigar", es decir, "el sistema de racionalidad subyacente a las prácticas punitivas" (Foucault, 1996, p. 146), en la que estaba particularmente interesado. No obstante, tiempo después de la publicación de Vigilar y castigar, en una entrevista de 1983 titulada “¿A qué llamamos castigar?”, recuerda a Nietzsche y afirma que:

[...] en nuestras sociedades contemporáneas ya no se sabe con exactitud qué es lo que se hace cuando se castiga, ni tampoco qué puede en el fondo justificar la punición: todo ocurre como si practicásemos un tipo de castigo en el que se entrecruzan ideas heterogéneas, sedimentadas unas sobre otras, que provienen de historias diferentes, de momentos distintos, de racionalidades divergentes (Foucault, 1996, pp. 150-151).

Si bien Foucault no se refiere al fundamento del "derecho a castigar", deja claro que una de las tareas más importantes consistiría en repensar "articulando el derecho, la moral y la institución, el sentido que se le puede conferir hoy a la punición legal” (Foucault, 1996, p. 151), algo que deja en evidencia la pertenencia del castigo a la esfera moral y la confusión que supone hablar de una ética del castigo. Porque el castigo, como juicio final que se homologa a una condena, recae sobre la corporalidad y un conjunto de cualidades características de una existencia que sobre un acto concreto y es, quizá, por eso que muchas veces quiere omitirse el significante castigo reemplazándolo benévolamente por otros tales como curar, tratar, reeducar.

\section{2 ¿Derecho al castigo?}

En 1941, Clarice Lispector publica Observaciones sobre el derecho a castigar, uno de sus primeros ensayos como estudiosa del derecho. Allí esgrime una serie de puntos que podrían nutrir la reflexión que venimos esbozando. Sostiene, pues, que no hay derecho a castigar y solo hay poder para castigar, porque la misma representación del crimen en la mente humana es inestable y relativa: "determinadas instituciones, en una época dada, al sentirse amenazadas en su solidez por la penetración de determinados actos, los considera 
punibles" (Lispector, 2012, p. 63). Siguiendo la pista del psicólogo social francés Gabriel Tarde, ella se pregunta cómo puede creerse tener el derecho de castigar si nadie puede alardear no ser delincuente en relación con un Estado social dado, pasado, presente o futuro. De aquí que, para ella, "no es a castigar a lo que hay derecho sino a defenderse, a impedir, a luchar" (Lispector, 2012, pp. 65-66) y el hecho de que castigar forme parte del lenguaje pretendidamente educativo y, más solapadamente, de la razón evaluadora no solo reactualiza el resquicio (o desquicio) de cuando la venganza era el objetivo de una sentencia (haciendo entrar en ella sentimientos individuales como el sadismo), sino que se usa el paliativo de la pena que sofoca el síntoma y cierra el proceso. Casi de modo similar en el que Foucault responde sobre este asunto, ella termina por decir que "sería preferible abandonar la discusión filosófica de un «fundamento del derecho a castigar», y, con la cabeza baja, continuar administrando morfina a los dolores de la sociedad" (Lispector, 2012, p. 67).

Sin embargo, el mundo parece ir derecho al castigo o, como asevera Fassin (2018), entramos, en el curso de estas últimas décadas, en una "época del castigo" en la cual se sanciona cada vez más y más severamente. El castigo aísla o excluye subjetividades y grupos de sujetos, produce y reproduce desigualdades, pero más fundamentalmente delinea una función punitiva que, en el acontecer cotidiano, se traduce en maltratos, amenazas, humillaciones, insultos, racismo, golpes que no dejan huella y hasta en diferentes formas de tortura. Nada de esto debería sorprendernos cuando el castigo del inocente y el castigo ilegal son formas habituales que, al día de hoy, siguen demostrando que las sociedades continúan castigando más allá de los principios ordenados por la ley, ¿o acaso no es precisamente en la escuela donde la sanción colectiva no es rara cuando el alumno "culpable de una falta" (Fassin, 2018, p. 67) no se denuncia o no es denunciado? Incluso bajo este mote, "culpable de una falta", en el marco de la razón evaluadora ¿no se castiga también el error, la falla o equivocación con malas notas o calificaciones que más tarde o más temprano serán perjudiciales para un(a) estudiante? Siguiendo a Fassin (2018) entonces, la ausencia de transgresión o prueba de transgresión no garantiza, por ende, la ausencia de castigo. Pero tampoco la transgresión convoca inevitablemente el castigo, pues "otras respuestas han sido imaginadas por las sociedades, incluso por los hechos más graves, pudiendo ir hasta una forma de indiferencia", así como "la realidad de una pena puede exceder con mucho su delimitación aparente, lo que revela la disyunción entre la enunciación y el cumplimiento del castigo" (Fassin, 2018, p. 42).

En el estudio filológico que Fassin (2018) ofrece respecto del verbo punir (castigar), podemos encontrarnos con una serie de términos que parecen formar cierta "cadena significante" del lenguaje punitivo, en el cual aparecen sintomáticamente palabras como: venganza, deuda, pago, compensación, reparación, retribución, resarcimiento, remuneración, recompensa, redención, expiación, enmienda, punición, pena, tormento, sufrimiento. Así como el verbo retribuir se inscribiría en acciones tales como "dar en cambio", pagar o hacer lo que es "debido", no podemos dejar de establecer una conexión con la atinada observación de que la compensación consiste entonces en "en una remisión y un derecho a la crueldad" (Nietzsche, 1997, p. 85). Pues, tal como analiza Fassin (2018), los términos de los cuales deriva el vocabulario del castigo ponen de manifiesto una restitución en relación con una deuda, la reparación de un acto censurable, el pago procedente de una obligación, lo cual forma una red semántica del intercambio que a partir del siglo primero aparecerá asociada al sufrimiento y con mayor fuerza en el léxico religioso durante el Renacimiento. De este modo, la red semántica del intercambio muta al dolorismo que hace del castigo un tormento, una "desgracia merecida" o un sufrimiento a infligir que termina por imponerse y diseminarse durante la colonización donde se confrontan violentamente las lógicas del intercambio y las del sufrimiento al tiempo que se imponen ciertos dispositivos penales.

En este contexto, Fassin se pregunta cómo y por qué se ha pasado, en las sociedades occidentales, de una lógica de la reparación a una lógica del castigo y de una economía afectiva de la deuda a una economía moral del castigo, y observa que el sufrimiento ocupa un lugar crucial en estos desplazamientos porque compensaría la falta. En este sentido, no deja de ser curioso, y un punto de coincidencia entre la razón evaluadora y la razón punitiva, que opere una especie de búsqueda de consentimiento o aceptación del sufrimiento infligido: así como la razón evaluadora busca incansablemente el consentimiento de quien se evalúa, -como también hemos 
visto anteriormente en Simmel- el castigo necesita convencer a quien se castiga de que acepte su sufrimiento de modo que una "hermosa ejecución" no solo era la que hacía confesar faltas y mostrar el arrepentimiento del condenado sino, sobre todo, la que lograba dar con su consentimiento en pos de su "salvación" (Fassin, 2018, p. 219).

Por tanto, a pesar de que los iluministas pretendían "humanizar el castigo" reemplazando; castigos por "corrección moral”; ejecuciones por "educación”; y crueldad por "disciplina”, cabría plantearse aquí hasta qué punto el castigo no se recicló en la corrección moral, las ejecuciones tomaron nuevas formas en la educación (no olvidemos la frecuencia con la que suele escucharse en las aulas la popular frase "me mataste" luego de alguna inquisición profesoral a algún estudiante) y la crueldad en la disciplina, algo a lo que Fassin parece estar atento cuando insta a no descuidar el mar de fondo de las permanencias frente a las oleadas de cambio regularmente anunciadas. Por eso se ocupa, por ejemplo, de explorar los rastros dejados por el cristianismo, aún en instituciones o prácticas consideradas laicas, en procedimientos cotidianamente naturalizados como la individualización (que personaliza la culpa a través del pecado en forma de falta), la imposición de sufrimiento (que proviene del fondo dolorista crístico y martirológico) y la moralización (que se relaciona con la teología de la redención saludable). Todo esto contra dimensiones colectivas, de compensación y reparación material, que hacen entrar a la escena a los juicios de desaprobación.

Fassin encuentra que el sufrimiento no es suficiente para caracterizar al castigo y, con una significación primordialmente simbólica, se agrega la reprobación cuya figura del acto reprobable consistiría, según Fassin (2018), en una "afrenta al valor", una "herida moral" como ataque a la "dignidad humana" en general, lo que pone de manifiesto las dimensiones simbólica, moral y afectiva del acto de castigar. Cabe preguntarse si no es precisamente esto lo que sucede en el acto de reprobación que realiza la razón evaluadora cuando castiga lo que puede considerar una "afrenta al valor" de lo evaluado (o del evaluador), una en la moral (de lo Mismo) y un ataque a su dignidad pretendidamente general (o, mejor dicho, universal). Algunas razones pueden dar cuenta de las múltiples situaciones en las que se lo usa: impedir la continuidad de un error, "aislar la causa de una perturbación para evitar su propagación”, “eliminar un elemento degenerado”, amedrentar, "crear una memoria”, pagar la falta, humillar, etc. ${ }^{4}$ Pero no todo parece quedar reducido meramente a dichas razones ni a la racionalidad en cuestión.

Durkheim asocia la pena a una "reacción pasional", algo que podría explicar sus excesos, su búsqueda de vergüenza o crueldad manifiesta que sería un tipo de suplicio suplementario y que da cuenta, para Fassin (2018), de un "goce del suplicio". Y que sería no otra cosa que lo que en el acto de castigar resiste su descripción como un hecho racional, una "pulsión más o menos reprimida cuyos efectos la sociedad delega en ciertas instituciones y profesiones" (Fassin, 2018, p. 134), del cual también gozan quienes asisten o participan del mismo. Así, a la sanción se le agrega cierta satisfacción por el sufrimiento del otro y las mismas instituciones educativas a veces incitan a (o naturalizan) la crueldad, algo que también se ve reforzado por el discurso de la severidad y que suele transmutar, como tanta pedagogía sádica ha mostrado en la historia de la educación, el poder de castigar en derecho de hacer sufrir. Esta relación de goce con el sufrimiento ajeno puede tomar formas indirectas y atenuadas, manifiestas u ocultas, ambiguas y negadas, pero no deja de ser un exceso al que las justificaciones e interpretaciones no pueden acceder del todo en sus más hondas metástasis.

Por último, no es menor el papel que Fassin le otorga a la colonización como la responsable de introducir el principio según el cual se individualiza la pena en alguien que ha sido juzgado como único sujeto responsable y que hace prevalecer la imposición de un dolor sobre la expectativa de una reparación, así como se deja sin lugar -o directamente se niega- la dimensión social y colectiva del problema, lo que contribuye al incremento de las desigualdades sociales. Esa distancia radical (y abismal), siempre moral, que se instituye entre quien juzga y la persona que es juzgada produce una alterización que da lugar a la inflexibilidad, e incluso a la crueldad, abriendo puerta a lo que Fassin (2018) llama "momento punitivo" (una "solución" que deviene ella misma problema). Es también lo que Butler (2009) encuentra en el modo de actuar de la condena como un modo rápido de postular una diferencia ontológica, entre quien juzga y quien es juzgado, y depurarse del otro. Se 
trata de una manera de instituir al otro como depósito de algún aspecto que desechamos de nosotros mismos y que, en el marco de la moralización que supone la condena, niega lo que el yo juzgador tiene en común con aquel sujeto que está siendo juzgado, purgando la propia opacidad y ejerciendo violencia (en nombre de cierta "ética") sobre quien se condena. Aquí podríamos situar otro vínculo de la razón evaluadora con la razón punitiva ya que incluso "En formas más mitigadas, la condena aún apunta a la vida del condenado" (Butler, 2009, p. 71), lo cual puede observarse directamente cuando evaluaciones y exámenes tienen efectos ontológicos sobre la vida de las gentes, o se convierten en una manera de comprender quién sería alguien o, como ha dicho Butler en una conversación al respecto:

[...] un sentido del sí mismo que valora el pensar o lo que tiene para ofrecer en clave de lo que resulta del puntaje obtenido. [...] Si no te va bien quedas devaluado [...] quedas condenado en el sentido de ser entendido como menos prometedor o menos productivo que los otros, lo que implica una reducción del propio horizonte, es decir, un señalamiento de lo que es posible y lo que no es posible para ese sujeto [...] eso termina por ser aceptado por el sujeto; porque el sujeto acepta la autoridad encarnada en ese juicio de valor o en esos estándares (en Giuliano, 2017, p. 185).

Así, la condena puede devenir un principio internalizado de sujeción en forma tal que se pierde de vista a esa autoridad externa "que impone y regula los principios de nuestra subjetividad" (Butler en Giuliano, 2017, p. 186) haciendo que calculemos nuestro valor, nos midamos y nos condenemos a nosotros mismos. El sentido de sí condenado así, a ser medido, exigido en transparencias medibles y forzado a seguir el ritmo calculado de las mediciones.

\subsection{La razón evaluadora en la sociedad punitiva y la sociedad punitiva en la razón evaluadora}

Tiempo antes que publicara Vigilar y castigar, Foucault ofrece un curso en el Collège de France donde se dedicó a explorar diferentes formas de lo punitivo al interior de la sociedad. En su primera clase delinea las principales formas de las tácticas punitivas, de las cuales interesa resaltar tres, para vincularlas con la racionalidad evaluadora:

I. La exclusión que, vía examen o ingreso restricto, directamente prohíbe la presencia de ciertas personas a la institución educativa.

II. La imposición de una compensación con respecto a un error o equivocación considerada falta y transformada en una obligación comparable a una deuda.

III. La marca que deja cierta cicatriz en un legajo (el aplazo o suspenso, según el caso), como una forma de poner un signo en el cuerpo o de imponerle una disminución virtual que inflige una "mancha simbólica" a su nombre, una humillación con la que se carga en la vida y hace mella en su status, lo que constituye un "elemento de memoria y reconocimiento" (Foucault, 2016, p. 23) según el cual el error o la equivocación (cual falta o infracción) ya no es lo que debe repararse, compensarse, reequilibrarse o borrarse, sino lo que debe subrayarse, escapar al olvido o quedar fijado en un pequeño monumento que gira alrededor de la vergüenza o la infamia.

Por otra parte, las formulaciones en cierto modo temporales del acto de reprobar o desaprobar pueden dar algunas pistas sobre cómo pervive la racionalidad punitiva en su interior. Pues aplazar o suspender, aloja en su interior una pena que demandará cierta cantidad de tiempo para responder a la insuficiencia, al error o las equivocaciones que toman forma de infracción y que, además de dejar huellas (subjetivas y administrativas), sugieren la contracción de cierta deuda para con la institución. En esto ha influido "la introducción del tiempo en el sistema de poder capitalista y el sistema de penalidad" que ya no castiga el cuerpo, sino "el tiempo por vivir" (Foucault, 2016, pp. 93-94). Entra en juego así una dimensión general del control social que Foucault (2016) llama lo penitenciario, a partir de la cual se activa un mecanismo de penalización de la existencia que requiere "encuadrar la existencia en una especie de penalidad difusa, cotidiana" y que introduce en el propio 
cuerpo social "prolongaciones parapenales, anteriores al aparato judicial" (Foucault, 2016, p. 228). De este modo, la vida escolar se inscribe en todo un juego de recompensas y castigos, en el que se advierte y se amenaza tanto como se ejerce una presión constante en el marco de un sistema graduado, continuo y acumulativo: así como las advertencias y castigos se sumaban y quedaban asentados en las cartillas de evaluación que se hacían de los obreros a comienzos del siglo XVIII en Francia, ejerciendo una presión cada vez más grande sobre el individuo porque de las anotaciones elogiosas dependían sus condiciones de empleo (y la ausencia de ellas denotaba una evaluación peyorativa), la libreta de estudiante -o boletín de calificaciones- hará las veces de cartilla y cada quien llevará ahí las marcas elogiosas o punitivas de su paso por la institución educativa -algo que, además, impactará en la sumatoria final de esas marcas (por lo general numéricas) que constituirán un promedio y en las condiciones de empleabilidad o acceso a determinadas oportunidades laborales-.

Así se instala "una trama ininterrumpida que extiende la justicia hasta la vida cotidiana; algo así como una capilarización de la instancia de juicio, e idas y venidas constantes entre lo punitivo y lo penal" (Foucault, 2016, p. 229), algo que manifiesta otra de las características de continuidad entre la razón punitiva y la razón evaluadora: la sociedad punitiva no solo requiere de vigilancia y control, sino de un saber sobre las gentes que se encuentra garantizado cuando se les somete a una prueba permanente, una especie de "juzgamiento permanente" -dirá Foucault (2016, p. 230)- en el que se produce un enfrentamiento e involucra una "decisión de culpabilidad". A esa prueba sin punto final, graduada y acumulativa, al margen de cualquier falta, que indaga a priori porque se funda en una sospecha general, que permite un control y una presión sin pausa tanto como seguir a cada quien en cada una de sus actitudes (y ver si es regular o irregular, ordenado o disipado, normal o anormal, división que autoriza una distribución graduada) Foucault (2016) la llama examen. De este modo, puede notarse que la sociedad punitiva es una sociedad examinadora y, por lo mismo, una sociedad disciplinaria que "liga a la actividad permanente de castigo una actividad conexa de saber, de registro", donde "El par vigilar-castigar se instaura como relación de poder indispensable para la fijación de los individuos en el aparato de producción y la constitución de las fuerzas productivas" (Foucault, 2016, p. 231). Es lo que hace que la escuela se convierta en un aparato que a la vez que transmite saber, normaliza, corrige, rectifica, produce, donde se margina a quien resiste o se le fija en "cierto punto, durante cierto tiempo, hasta una decisión del tribunal" (Foucault, 2016, p. 244).

Así, el control, la gestión, la organización del tiempo de la vida se integran en la continuidad de la producción y la ganancia, que no es otra cosa que el tiempo de la capitalización en el que se aplica un "modelo que homogeniza" (somete a las mismas leyes y "ventajas"), un "esquema moralizador" (que pone a la gente en deuda, en un sistema de obligación) y una "operación de sujeción" (Foucault, 2016, p. 247) a las normas que el mismo tiempo de la capitalización establece. De ahí que la escuela también sea una institución que se hace cargo del control directo o indirecto de la existencia en lo que ataña, por ejemplo, a la corporalidad, la sexualidad y las relaciones interpersonales. Pero, para que el tiempo de la vida pueda ser homogéneo con el tiempo de la producción, sobre todo en instituciones como la escuela, se requiere de una "función de juicio permanente" o una "instancia de juicio, una especie de judicatura ininterrumpida, que haga que los individuos estén siempre sometidos a algo como una instancia judicial que evalúa, impone castigos o da recompensas" y, a este respecto, un tipo de discursividad (con su juicio, vigilancia, calificaciones y contabilidad) que "retoma lo cotidiano, lo individual, lo íntimo, lo corporal, lo sexual en cierto espacio definido" (Foucault, 2016, pp. 250-251) por la escuela.

Tales elementos no pueden desvincularse de la situación de poder en la que una autoridad jerárquicamente situada ajusta a la normatividad el discurso que emite y se presenta como un hecho social "frente al cual no se puede hacer nada" y funciona como "una regla en cuyo nombre se castiga o recompensa" (Foucault, 2016, p. 252) sin descanso. Siguiendo este planteamiento, todo ello conforma una "red de instancias cognitivaspunitivas epistemológico-judiciales", cuya forma de intervención general es el "examen perpetuo" y desde donde se describe al sujeto "en función de su distancia posible o real, respecto a algo que se define, ya no como 
el bien, la perfección, la virtud, sino como la normalidad" (Foucault, 2016, p. 252). La normalidad, que no es forzosamente la media, es una norma condición de ejercicio para dicha discursividad.

Dar órdenes, reglamentar, recompensar, castigar, hacer comparecer ante una instancia de juicio, trama el discurso normalizante-punitivo que va a "describir, analizar, fundar la norma y hacerla prescriptible, persuasiva” (Foucault, 2016, p. 276), que podrá ser al mismo tiempo el discurso del docente como del juez quienes vigilan y pueden separar al normal del anormal-.

\subsection{Colofón: para una defensa del error, en torno a una justicia (pedagógica) de alteridad}

Si hay un punto de encuentro entre Adorno y Foucault, en relación con la actuación ética, Butler (2009) lo sitúa en la asunción del error como constitutivo de lo que somos. Lo cual:

[...] no significa que seamos solo error o que todo lo que decimos sea descaminado o equivocado, pero sí implica que nuestro obrar está condicionado por un límite constitutivo del cual no podemos dar cabal cuenta, y esa condición es, paradójicamente, la base de nuestra responsabilidad (Butler, 2009, p. 152).

Históricamente, la pedagogía moderna ha castigado, descalificado y reprobado el error, aun siendo constitutivo de lo que somos, lo que se constituye en un problema ético-político-educativo que tiene vigencia en la actualidad cuando, incluso, ciertas didácticas evaluativas intentan convencer de que sería "una oportunidad para aprender" pero sin desprenderse de las marcas, las consecuencias administrativas y los procedimientos punitivos, claro. En la conversación anteriormente citada, Butler retoma a Nietzsche cuando dice que "la verdad no es nada más que una serie de errores conectados entre sí de alguna manera" y de ahí parte para responder a la problemática en cuestión que descuida que "somos criaturas atravesadas por la perspectiva, siempre estamos viendo parcialidades" (en Giuliano, 2017, p. 186), lo que implica que no hay mirada sin error. Por eso le parece clave que se piense un poco más desde el humor en educación y con respecto a cometer errores, sobre lo que dice:

[... " comete tu error y encuéntralo magnífico, comete tu error y encuéntralo enorme". Se trata de pensar una manera de vivir el error como una forma de aceptar nuestra perspectiva limitada, aceptándolo como parte de lo que implica estar vivo, ser, devenir. Esto es muy distinto a pensar a la persona donde el error es marcado como falta (Butler en Giuliano, 2017, p. 187).

Se trata de una manera de vivir el error afirmativamente, como una dimensión de lo humano que forma parte de lo in-evaluable o lo in-juzgable. Algo que no deja de ser un problema en la sociedad punitiva y la educación dominada por la razón evaluadora, frente a las cuales podría evocarse a Nietzsche, en Zaratustra, cuando decía que la mirada del juez es siempre la mirada del verdugo con su fría cuchilla y por eso exhortaba a inventar una justicia que absuelva a todos excepto a los que juzgan.

Como Lispector (2011) cuando enseña que de una vida entera "lo que se salva a veces es tan sólo el error" (p. 136), porque es nuestro espejo donde vemos lo que en silencio hacemos de otros, porque es el modo en que vemos abrirse la vida en su carne y nos asombra permitiéndonos ver la materia de vida: el barro vivo. Por eso no hay que dejar que lo acorralen, que lo maten, que nos maten. En otras palabras, que siga creciendo el cementerio de los errores fusilados en su fuerza desorientada mientras un dios fabricado a último momento bendice la maldad organizada y la justicia estúpida que sostiene las paredes de la certidumbre que siempre justifican que "no hay nada que hacer" y se procure no entender. Como quienes, "para que la cosa funcione", se exigen como primer deber hacerse el tonto y no ejercer la propia rebeldía porque, si no se hace el tono, la escuela se estremece. Se olvida que debajo de ella está el terreno, el suelo donde una escuela otra podría levantarse, pero entender esto o aquello desorganiza. ¿Descoloniza? Sí, a los condenados de la tierra. Se llamen error, equivocación o tropezón. Una manera de entrar en la vida que no tiene puerta, y entender lo que es peligroso entender, para no ser un destacamento policial con cientos de ametralladoras evalúo-correctoras y sea esa nuestra "honorabilidad". Y, sin darnos mucha cuenta, lo que está en juego es una justicia otra. 
Una justicia de alteridad, quizá, que no sepa, pero esté dispuesta a entender que hay desesperación cuando falla el habla y, en cierta mudez, solo queda el grito desarticulado como señal. Una justicia de alteridad, quizá, que no olvide la intimidad que existe entre el miedo y la lucha. Una justicia de alteridad, quizá, que se mire a sí misma y vea también en nosotros la oscuridad y el barro vivo. Y que, por esto mismo, no entregue una falla ( $y$ un fallo) a una maldad que pueda cometer libremente y con aprobación su fusilamiento aguardado. Y es que, cuando el justiciero (pedagógico) mata, no está protegiendo a nadie ni eliminando un peligro social: está castigando a alguien inocente. Cierto es entonces que, como Lispector (2011), podríamos querer algo mucho más áspero y más difícil, para no olvidar, que gravite el pensar y el sentir, desde donde puede levantarse alguna rebelión, pero también algún tiempo libre otro. Sin más aplazamiento, entonces, queramos el suelo.

\section{REFERENCIAS}

Butler, J. (2009). Dar cuenta de si mismo. Violencia ética y responsabilidad. Buenos Aires, Argentina: Amorrortu.

Butler, J. (2010). Marcos de guerra. Las vidas lloradas. Buenos Aires, Argentina: Paidós.

Capurro, R. y Nin, D. (2018). Extraviada. Rosario, Argentina: una piraña.

Durkheim, É. (1997). La educación moral. Buenos Aires, Argentina: Losada.

Fassin, D. (2018). Castigar. Buenos Aires, Argentina: Adriana Hidalgo.

Foucault, M. (1996). La vida de los hombres infames. La Plata, Argentina: Altamira.

Foucault, M. (2009 [1975]). Vigilar y castigar: nacimiento de la prisión. Buenos Aires, Argentina: Siglo Veintiuno.

Foucault, M. (2016). La sociedad punitiva: curso en el Collège de France (1972-1973). Buenos Aires, Argentina: Fondo de Cultura Económica.

Giuliano, F. (2017). Rebeliones éticas, palabras comunes. Conversaciones (filosóficas, politicas, educativas) con Judith Butler, Raúl Fornet-Betancourt, Walter Mignolo, Jacques Rancière, Slavoj Žižek. Buenos Aires, Argentina: Miño y Dávila.

Giuliano, F. (2018). La pregunta que luego estamos si(gui)endo: manifestaciones de una cuestión ética-geopolítica. En Facundo Giuliano (Comp.), ¿Podemos pensar los no-europeos? Ética decolonial y geopolíticas del conocer (pp. 11-68). Buenos Aires, Argentina: Del Signo.

Giuliano, F. (2019a). ¿ Tienes razón evaluación? Notas para la profundización de una noción filosófica de la educación. Revista Electrónica Educare, 23(1), 1-22. Recuperado de https://www.scielo.sa.cr/pdf/ree/v23n1/1409-4258ree-23-01-405.pdf

Giuliano, F. (2019b). Escuela y colonialidad. Variantes e invariantes (estéticas) de la clasificación social. Nawi. Arte diseño comunicación, 3(2), 93-109. Recuperado de http://www.revistas.espol.edu.ec/index.php/nawi/article/ view/554/428

Giuliano, F. (2019c). Entonces, ¿qué es un dispositivo? De la matriz colonial de poder a los dispositivos (pedagógicos) contemporáneos. Voces de la Educación, 4(8), 28-68. Recuperado de https://dialnet.unirioja.es/servlet/articulo? codigo $=7017237$

Haynes, F. (2002). Ética y escuela. ¿Es siempre ético cumplir las normas de la escuela? Barcelona, España: Gedisa.

Lispector, C. (2011). Para no olvidar. Buenos Aires, Argentina: El cuenco de plata.

Lispector, C. (2012). Dónde se enseñará a ser feliz. Buenos Aires, Argentina: Grupal-Siruela.

Mèlich, J. (2014). Lógica de la crueldad. Barcelona, España: Herder.

Mercado, T. (1990). En estado de memoria. Buenos Aires, Argentina: Ada Korn.

Miller, A. (1998). Por tu propio bien. Raices de la violencia en la educación del niño. Barcelona, España: Tusquets.

Nietzsche, F. (1997) La genealogía de la moral. Un escrito polémico. Madrid, España: Alianza.

Perrenoud, P. (2015 [1997]). La evaluación de los alumnos. De la producción de la excelencia a la regulación de los aprendizajes. Entre dos lógicas. Buenos Aires, Argentina: Colihue. 
Lic. Facundo Giuliano. Razón evaluadora/razón PUnitiva: Relaciones y Complicidades (o dos Caras DE...

Segato, R. (2010). Las estructuras elementales de la violencia. Ensayos sobre género entre la antropología, el psicoanálisis $y$ los derechos humanos. Buenos Aires, Argentina: Prometeo.

Segato, R. (2018). Contra-pedagogias de la crueldad. Buenos Aires, Argentina: Prometeo.

Simmel, G. (2007). Pedagogía escolar. Madrid, España: Gedisa.

Simons, M. y Masschelein, J. (2014). Defensa de la escuela. Una cuestión pública. Buenos Aires, Argentina: Miño y Dávila.

Thorndike, R. L. y Hagen, E. P. (1989). Medición y evaluación en psicología y educación. México: Trillas.

Tyler, R. (1971). Efectos educacionales de los exámenes en Estados Unidos de América. En: Lawerys, J. y Scalon, D. (Comps.), Examen de los exámenes (pp. 239-248). Buenos Aires, Argentina: Ángel Estrada.

\section{NoTAS}

1 Según Durkheim (1997), el trato más riguroso empleado por esa educación severa consistiría “simplemente" en golpes dados con la mano (o con una varita) o bien en una privación de alimentos.

2 No deja de ser curioso que, en la misma lección, Durkheim refiera al orgullo de un maestro alemán por las 2.227.303 correcciones corporales dispensadas durante su carrera y mencione la "fiesta anual del látigo" celebrada en Alemania.

3 Sobre el utilitarismo como teoría consecuencialista del castigo, Fassin (2018) muestra al respecto de la "disuasión" pretendida que, a pesar de que el castigo sea cada vez más duro, la actividad delictiva no declina y las medidas menos restrictivas junto a políticas menos represivas alcanzan los mejores resultados en detrimento de la propuesta represiva del utilitarismo.

4 Las razones entrecomilladas son aportadas por Fassin (2018).

Todos los derechos reservados. Universidad de Costa Rica. Esta revista se encuentra licenciada con Creative Commons. Reconocimiento-NoComercial-SinObraDerivada 3.0 Costa Rica. Correo electrónico: humanidades@ucr.ac.cr/ Sitio web: http: //revistas.ucr.ac.cr/index.php/humanidades

CC BY-NC-ND 